\title{
Risks and opportunities of assisted colonization: the perspectives of experts
}

\author{
Irma Kracke', Franz Essl ${ }^{1,2}$, Klaus Peter Zulka ${ }^{3}$, Stefan Schindler ${ }^{3,4}$ \\ I BioInvasions, Global Change, Macroecology-Group, Department of Botany and Biodiversity Research at the \\ University of Vienna, Rennweg 14, 1030 Vienna, Austria 2 Centre for Invasion Biology, Department of Botany \\ \& Zoology, Stellenbosch University, Matieland 7602, South Africa 3 Environment Agency Austria, Spittelauer \\ Lände 5, 1090 Vienna, Austria 4 Community Ecology and Conservation Research Group, Faculty of Envi- \\ ronmental Sciences, Czech University of Life Sciences Prague, Kamýcká 129, 16500 Prague, Czech Republic \\ Corresponding author: Stefan Schindler (stefan.schindler@umweltbundesamt.at)
}

Academic editor: Chris Margules | Received 4 August 2021 | Accepted 29 October 2021 | Published 15 December 2021

http://zoobank.org/8460DF8B-06EE-4591-9FF7-45BCC8CE397B

Citation: Kracke I, Essl F, Zulka KP, Schindler S (2021) Risks and opportunities of assisted colonization: the perspectives of experts. Nature Conservation 45: 63-84. https://doi.org/10.3897/natureconservation.45.72554

\begin{abstract}
Owing to climate change and other anthropogenic environmental changes, the suitability of locations is changing for many biota that consequently have to adapt in situ or to move to other areas. To mitigate the effects of such pressures, assisted colonization is a conservation tool developed to reduce extinction risks by intentionally moving and releasing an organism outside its native range, and thus, to facilitate tracking changing environmental conditions. This conservation tool has been proposed for threatened animals or plants that presumably cannot adapt in situ or follow environmental changes by dispersal or migration. However, there have been contentious debates about the shortcomings and risks of implementing assisted colonization. For this reason, we evaluated the specific opinions of global experts for assisted colonization on potential risks and opportunities that this approach offers. For this purpose, we used an online survey targeted at authors of scientific publications on assisted colonization. The majority (82\%) of the 48 respondents were in favor of applying assisted colonization for species that are at risk of global extinction due to anthropogenic environmental change. Most respondents agreed that assisted colonization should be considered only when other conservation tools are not available and that certain preconditions must be met. Some of these were already highlighted in the IUCN guidelines for assisted colonization and include a completed risk assessment, clearly defined management plans and secured political as well as financial support. The advocacy of assisted colonization in response to anthropogenic global environmental changes was only weakly dependent on the geographic origin of the experts and their working background.
\end{abstract}

Copyright Irma Kracke et al. This is an open access article distributed under the terms of the Creative Commons Attribution License (CC BY 4.0), which permits unrestricted use, distribution, and reproduction in any medium, provided the original author and source are credited. 
Regarding possible risks, most of the respondents were concerned about consequences like failure of the long-term establishment of the translocated species and the transmission of diseases and invasiveness potentially endangering native biota. To keep these risks as low as possible most of the experts agreed that a target area must have a reasonable carrying capacity to sustain a minimum viable population and that adaptive management should be implemented. Careful evaluation of assisted colonization projects is required to generate further evidence that needs to be considered for further developing conservation tools for the Anthropocene.

\section{Keywords}

Biodiversity conservation, climate change, conservation management, survey, tools, translocation

\section{Introduction}

Climate change is rapidly becoming an increasingly pervasive pressure on species distributions (Dawson et al. 2011; Urban 2015). This novel pressure acts on top of other anthropogenic impacts such as habitat loss, water extraction, toxic pollutants, and invasive alien species (Grimm et al. 2013), which are already threatening the survival of roughly a quarter of extant species (Ma et al. 2018; Díaz et al. 2019). In response to all these unprecedented environmental changes, species are increasingly shifting their ranges (Parmesan and Yohe 2003; Root et al. 2003). Thus, climate change and other anthropogenic pressures create a huge challenge for species conservation and call for the identification of novel tools for ensuring species survival in the Anthropocene (Loss et al. 2011; Wessely et al. 2017; Genovesi and Simberloff 2020).

In general, the survival of species under rapid environmental change will depend on the interplay of in situ adaptation and the capacity of species to track environmental changes in space, i.e. to colonize regions that have become newly suitable (McLachlan et al. 2005; Semenchuk et al. 2021). In situations where in situ adaptation is unlikely, translocation of organisms by assisted colonization may represent an option - at least for some species - (Hällfors et al. 2017; Lloyd et al. 2019) and has been proposed as a novel conservation tool to complement current conservation strategies (Hällfors et al. 2014).

Assisted colonization, also known as assisted migration, managed relocation or benign introduction, is commonly understood as the intentional movement and release of an organism to regions outside its native range (IUCN/SSC 2013). Originally, this conservation tool has been proposed for species whose suitable climatic space is projected to disappear entirely during the next decades in their current range (Hällfors et al. 2017), but for which suitable climatic conditions probably will exist outside their current range. In these cases, future survival may critically depend on species ability to colonize newly suitable climatic space (Minteer and Collins 2010; Ste-Marie et al. 2011). Assisted colonization thus aims to actively support range shifts towards newly suitable regions (Hällfors et al. 2014), and it has been proposed to represent an effective climate change adaptation strategy (Thomas 2011). 
Some of the earliest assisted colonization projects were implemented to resolve human-animal conflicts, to increase game populations, and for conservation purposes (Fischer and Lindenmayer 2000). In recent years, an increasing number of assisted colonization events have been implemented worldwide. Examples are the relocation of swamp tortoise (Pseudemydura umbrina) in Australia (Seddon et al. 2015), the introduction of the conifer Torreya taxifolia in regions north of its current range the USA (McLachlan et al. 2007), and the introduction of two butterfly species (Melanargia galathea, Thymelicus sylvestris) north of their current range in the United Kingdom (Willis et al. 2009). All these species are assumed to become threatened by climate change in their current range, and thus assisted colonization was deemed to be a useful conservation strategy.

In 2013, the IUCN published official guidelines for conservation translocations of species. There, assisted colonization is defined as the intentional movement and release of an organism outside its indigenous range to avoid extinction of populations of the focal species. It is stated that assisted colonization should be carried out primarily where protection from current or likely future threats in the current range is deemed less feasible than at alternative sites. The term assisted colonization includes a wide spectrum of activities, from those involving the movement of organisms to areas that are both distant from the current range and separated by unsuitable areas to those involving small range extensions into areas adjacent to the current range. A recommended feasibility assessment should include a balance of expected conservation benefits against the costs and risks of both the translocation and alternative conservation actions (IUCN/ SSC 2013).

Assisted colonization has become a subject of substantial controversy in the conservation community. Contested issues are, for instance, the potential scope and feasibility of this conservation tool, the risks associated with the likelihood of translocated species negatively affecting the biotic environment in their new range, e.g. by becoming invasive, carrying diseases or parasites, and the risk of disrupting historical evolutionary and ecological processes (Hoegh-Guldberg et al. 2008; Ricciardi and Simberloff 2009; Schwartz et al. 2009; Seddon et al. 2009; Minteer and Collins 2010; Loss et al. 2011; Probert et al. 2019). Besides, even if assisted colonization is implemented following a careful risk assessment, it is possible that there are unintended and unpredictable consequences (Ricciardi and Simberloff 2009, 2014), mainly because the impacts of introduced species are highly context-specific and thus substantially vary spatio-temporarily (Ricciardi and Simberloff 2009; Gray et al. 2011). Therefore, some conservationists recommend focusing on traditional conservation tools such as expanding protected areas or improving habitat connectivity (Hunter 2007; Vitt et al. 2009; Javeline et al. 2015).

However, other conservationists argue that assisted colonization involves risks that can be identified ex ante and successfully contained (Sax et al. 2009). For example, it has been argued that adverse effects on native species in the recipient region can be avoided when the focal species is translocated within the same biogeographic region and the target region has no local endemics (Thomas 2011). Another line of argument is that "the consequences of doing nothing would be far worse" than applying a species conservation strat- 
egy that has certain limitations (Minteer and Collins 2010). Assisted colonization is also considered as a management tool that fills the gap between species migration capability and the expected velocity of climate change (Ste-Marie et al. 2011). Additionally, assisted colonization is an approach that also encapsulates societal and normative issues (Aubin et al. 2011; Burbidge et al. 2011). Further, solutions for financial, logistical and legal aspects are crucial for successful implementation (Hunter 2007; Hoegh-Guldberg et al. 2008).

Given the diversity of aspects to be considered and the diversity of opinions appearing in the published literature, we evaluated in this study the views of conservation experts on assisted colonization via an online survey. Specifically, experts who had authored scientific articles on assisted colonization in scientific journals were invited to participate in the survey, because the views of scientists working on assisted colonization on different aspects of usefulness and risks of this management strategy are particularly relevant, because they should have the deepest insights and have experienced particular obstacles or risks to be highly important. The questions were dealing with four themes, i.e. usefulness, risks, acceptance, and implementation and a combination of closed and open questions were used in order to obtain both, (i) differences in the proportion of experts agreeing to specific questions and suggested options for answers, and (ii) additional clarifications and recommendations on the aspects addressed. We argue that expert opinions regarding assisted colonization should be influenced by the disciplinary background of experts and their region of origin, because environmental conditions as well as the culture of nature conservation are strongly context-specific. For this reason, we also investigated the role of different backgrounds of respondents (e.g. countries of origin, focal study species) on the attitude towards assisted colonization. Finally, we provide a synthesis of the expert views expressed in this survey and we provide recommendations to take into consideration for future application of assisted colonization.

\section{Methods}

\section{Surveying expert opinions}

To assess opinions held on specific issues of environmental management, surveys of expert target groups have been proven effective (Donlan et al. 2010; Javeline et al. 2015; Braun et al. 2016; Pe'er et al. 2017, 2019). Such surveys allow the collection of current knowledge and opinions on specific issues, and if directed towards experts, they facilitate the provision of a synthesis of views held by this target group.

\section{Identifying the target audience}

For this study, we considered authors of publications on assisted colonization in international scientific journals. Thus, we collected all scientific publications that have dealt with assisted colonization and collected the contact details of the authors. For this purpose, first we researched and evaluated scientific articles in Scopus (www.scopus.com) 
using the term "assisted colonization" and the related search terms "assisted migration", "conservation strategies", "relocation", "moving species", "translocation of species", "climate change and threats to species", "benign introduction", "risks climate change species", "reintroduction species", "climate change impacts on species".

Secondly, a further selection was made based on titles and abstract, i.e. only articles that dealt with the topic assisted colonization were selected. In addition, "snowballing" was used (Wohlin 2014). Based on the reference lists of the selected articles, additional articles were identified that corresponded with the research criteria mentioned above. Finally, the e-mail addresses of the lead authors and all co-authors and their affiliations were extracted from the articles or researched on the internet.

Overall, the final sample consisted of 264 authors (incl. co-authors) of articles on assisted colonization. They authored 89 articles that were affiliated with 23 countries. Most of these countries lie in the geographical regions of North America, Europe and Oceania. Researchers from these three regions made up $95 \%$ of the total sample (Suppl. material 1: Fig. S1a).

\section{Survey design and analysis}

In April and May 2019, a web-based survey (www.soscisurvey.de) of expert views on assisted colonization was conducted. The 254 authors were informed by email with an invitation link to participate in the survey. The survey questions were based on previous original research on assisted colonization. For the individual survey questions, Likert-style survey items (Likert 1932) were used - i.e. statements or questions that respondents evaluate from a provided bipolar response scale. Additionally, participating experts could provide open answers and suggestions to some questions.

Overall, the questionnaire contained nine questions with several answer options. The survey questions were divided into five different sections: usefulness, risks and risk mitigation, acceptance, implementation, and summary statements. At the end of the questionnaire, several personal questions were asked to retrieve relevant characteristics of the population of responding experts. In the original survey the term "assisted migration" was used instead of "assisted colonization". However, throughout this manuscript, we finally applied the term assisted colonization to achieve consistency with the terminology in the IUCN guidelines. The entire questionnaire can be found in the Suppl. material 2.

\section{Data analyses}

First, a descriptive analysis of the collected data was carried out to illustrate the responses to the survey questions. Therefore, the response behavior of the respondents is presented in percentage distributions for the Likert-scale categories.

For assessing whether scientists from different parts of the world had differing opinions, the participating experts were assigned according to their affiliations to continents. We tested for significant differences $(p$-value $<0.05)$ among the medi- 
ans of the different groups using a Kruskal-Wallis one-way ANOVA (McKight and Najab 2010). In the event that a significant difference could be identified among groups, Mann-Whitney $U$ post hoc tests were performed to determine which of the groups differed significantly from the others (Wolf and Best 2010; Bortz and Schuster 2010). Resulting test statistics were converted into Cohen's d to assess the size of the detected effects.

For assessing whether working background affected the view of experts on assisted colonization, we used the proportions of respondents' work time allocated for each of the five activities (i) research on assisted colonization, (ii) climate change impacts, (iii) biodiversity, (iv) applied conservation management and (v) conservation policy (see Suppl. material 2) as predictors and the answers to two questions selected from the summary statements (i.e. (i) "Assisted colonization should be recognized as an effective tool for species conservation but with potential risks that need to be carefully addressed" and (ii) "Assisted colonization should only be implemented if exhaustive assessments are made that conclude that it will not cause a decline in the conservation status of any species native to the target area") as criteria by conducting correlation analyses using the Spearman rank correlation coefficient. Resulting test statistics were converted into Cohen's d to enable comparisons of effect sizes with the other statistical tests.

\section{Results}

\section{Respondents and their main work fields}

Of 264 invited experts on assisted colonization, 48 (18.2\%) participated in the online survey and were assigned according to their place of research to continents (Suppl. material 1: Fig. S1B). Of these, 33 were male, 11 were female, and four respondents gave no information about their gender. The participating experts used an average of $13.2 \%$ $( \pm 17.0 \mathrm{SD})$ of their work time in the past five years to conduct research on implementation of assisted colonization. A further $17.4 \%$ ( \pm 17.2 SD) used to conduct other kinds of research on climate change impacts on biodiversity, and a further $26.9 \%( \pm 23.3$ SD) on yet other kinds of research on biodiversity and nature conservation. The respondents dedicated a further $18.3 \%( \pm 20.1$ SD) of their work time for applied conservation management and $9.2 \%( \pm 13.3 \mathrm{SD})$ to conservation policy. A majority of the experts worked on several ecosystems, $59 \%$ stated that they worked in forests, 33\% worked in grasslands, $26 \%$ in mountains, $10 \%$ in marine and in urban ecosystems, respectively, $8 \%$ in coastal, freshwater and tundra ecosystems, respectively, and $6 \%$ in agricultural ecosystems.

\section{Usefulness of assisted colonization}

The vast majority (85\%) of the respondents strongly agreed or agreed that assisted colonization should be considered to be applied when a focal species is threatened 
by global extinction caused by climate change and $79 \%$ of the respondents strongly agreed or agreed on considering $\mathrm{AC}$ when threats are related to anthropogenic pressures other than climate change (e.g. fragmentation, habitat loss, competition, predation, pathogens) (Fig. 1A). There was little agreement for applying assisted colonization for preventing global (27\%) species extinction caused by natural causes (e.g. rarity, endemism). For all kinds of threats (climate change, other anthropogenic threats, natural causes), lower agreement values were obtained for preventing regional instead of global species extinction (Fig. 1A).

When asked to select criteria to identify species for assisted colonization, $91 \%$ of the experts strongly agreed or agreed that suitable species are those "whose extinction risk could not be reduced despite the implementation of conservation strategies other than assisted colonization" (Fig. 1B). A further $79 \%$ strongly agreed or agreed with the application of the criterion extinction risk, expressed e.g. by the Red List status of a species (cf. IUCN 2021). The criteria related to small climatic niches, long generation time when compared to the velocity of climate change, being a keystone species or a species that is relevant for ecosystem functions and for ecosystem service provision received $>67 \%$ agreement among respondents. Low genetic variation and phylogenetic uniqueness were considered least relevant (37\% and $41 \%$ agreement).

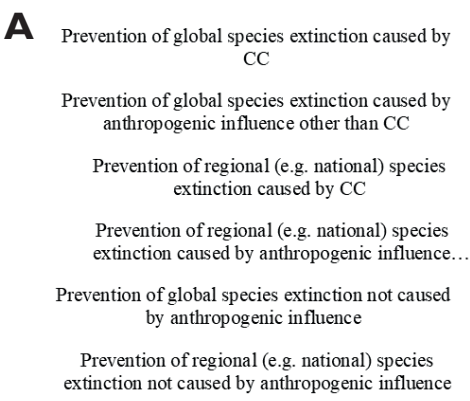

\section{B}

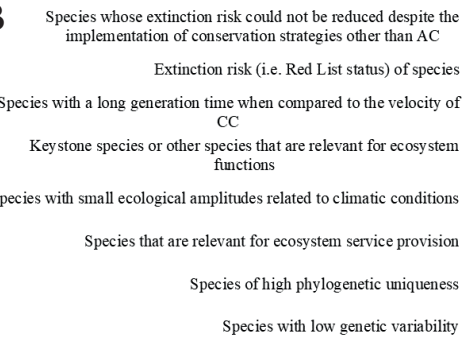

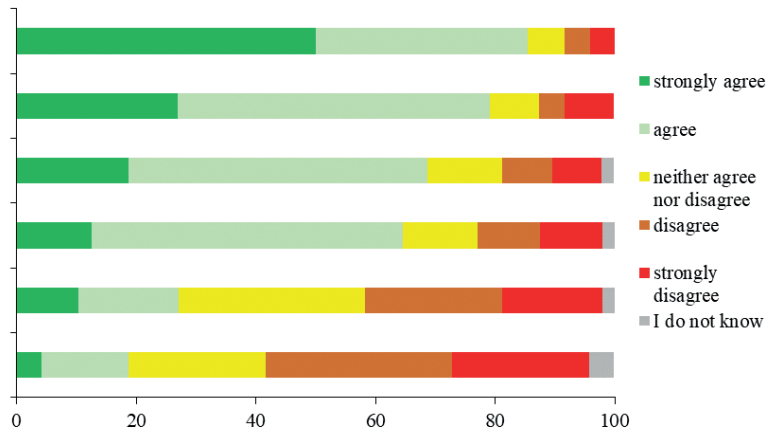

Experts (\%)

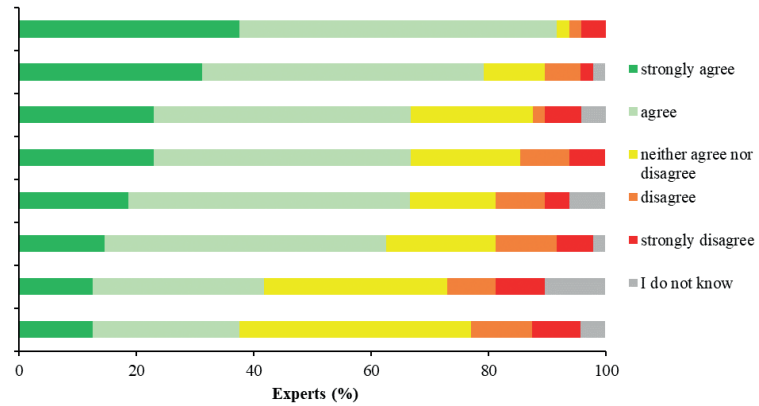

Figure I. Answers $(\mathrm{n}=48)$ to the questions $\mathbf{A}$ "For which kinds of threats to species, assisted colonization (AC) should be applied?, and B "Which should be the criteria to identify species for assisted colonization?". 


\section{Risks and risk mitigation of assisted colonization}

More than half of the experts considered the three risks of failure, i.e. biotic constraints, abiotic constraints, and human impacts, to be important or very important with only marginal differences among the risks (Fig. 2A). Likewise, the majority of experts estimated specified risks for the native biota of the target area to be of high importance (Fig. 2B); in particular, there was strong agreement on the high importance of transmission of diseases $(71 \%)$, increased competition with native species $(60 \%)$, and displacement of native species (58\%).

On reducing the risks of failure, $75 \%$ of the participating experts held the opinion that selecting a target area with a carrying capacity to sustain a minimum viable population is very important (Fig. 3A), closely followed by measures to implement adaptive management to minimize the risk of failing to establish in the target area $(70 \%)$ and identifying and protecting climate change refugia for the target species $(62 \%)$.

When it comes to risk mitigation for native biota in the recipient region, $74 \%$ of the respondents stated that the most important aspect was monitoring of the target region and areas adjacent to timely detect negative impacts (Fig. 3B). Other measures, i.e. implementation of adaptive management to minimize the risk for the biota of the

A

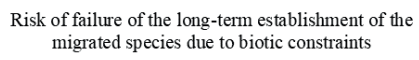
migrated species due to biotic constraints

Risk of failure of the long-term establishment of the migrated species due to abiotic constraints

Risk of failure of the long-term establishment of the migrated species due to human impacts

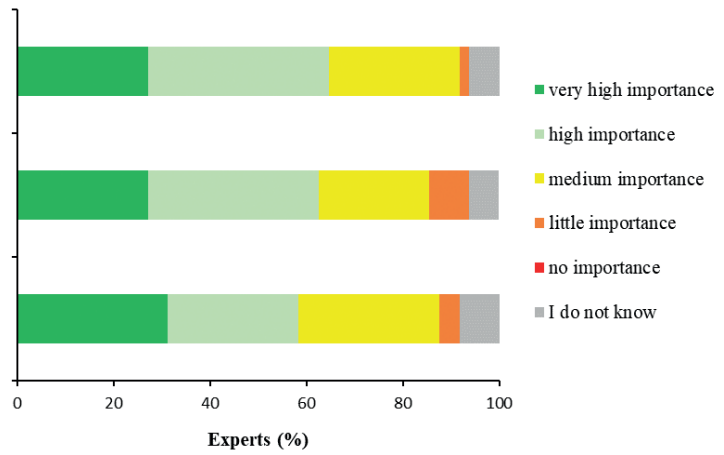

B

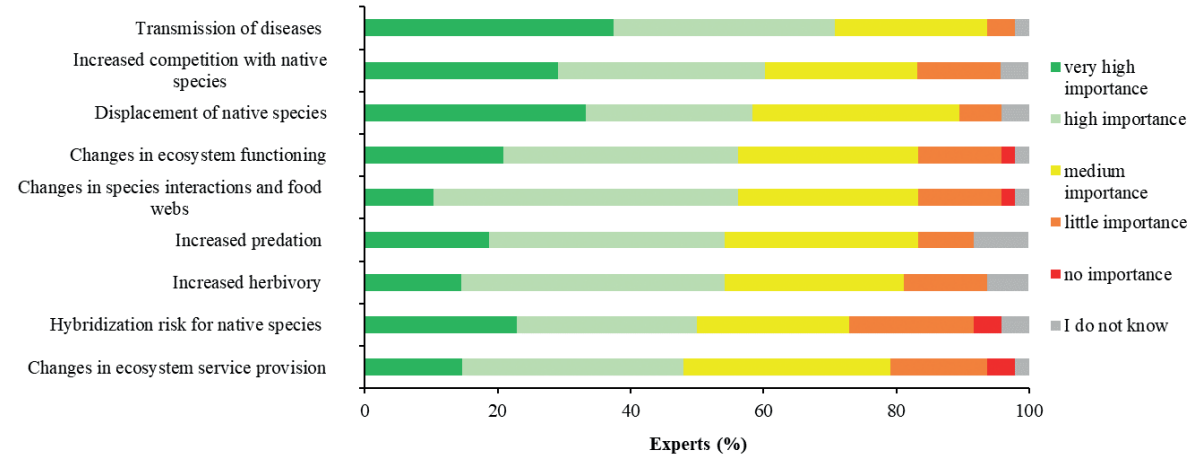

Figure 2. Answers ( $\mathrm{n}=48)$ to the questions $\mathbf{A}$ "How would you consider the importance of the following potential risks of failure for implementing assisted colonization?", and B "How would you consider the importance of the following potential risks of assisted colonization for native biota of the target area?". 
A
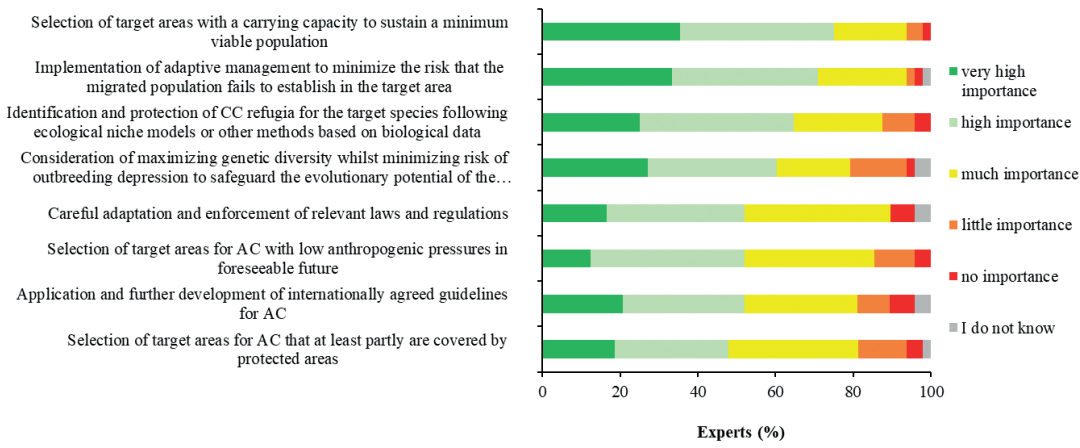

B
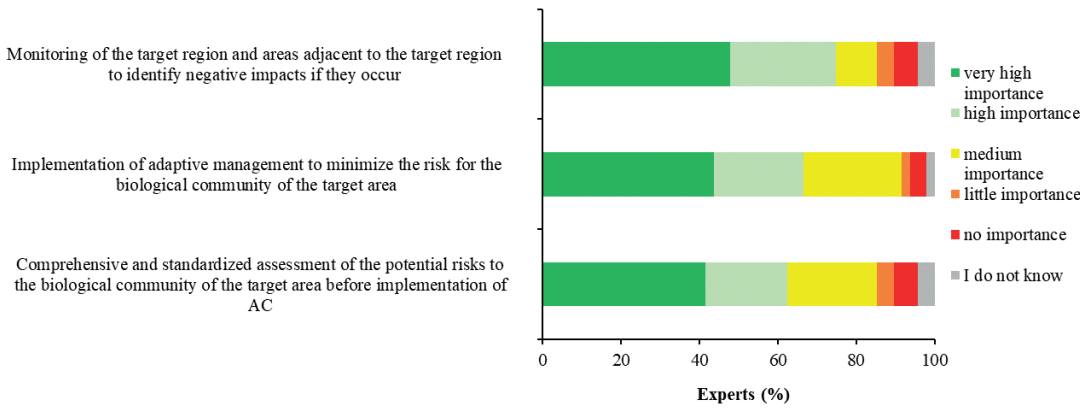

Figure 3. Answers $(\mathrm{n}=48)$ to the questions $\mathbf{A}$ "How would you consider the importance of the following measures to reduce the risk of failure", and B "How would you consider the importance of the following measures to avoid risks for native biota and ecosystems?”.

target area and comprehensive and standardized assessment of the potential risks to the biological community of the target area before implementation also received support from a majority of experts ( $66 \%$ and $62 \%$, respectively).

\section{Acceptance and implementation of assisted colonization}

A total of $81 \%$ of the respondents strongly agreed or agreed that long-term financial and political commitment in the target area is required for assisted colonization projects to be successful (Fig. 4A). A high level of agreement (72\%) was also shown for the statement that the political stance including relevant laws and regulation on assisted colonization projects should be assessed. The other three statements ("full authorization by government agencies", "assessment of citizen attitudes", "socio-economic impact studies") were more controversial, but still a majority of respondents (> 56\%) agreed or strongly agreed with them (Fig. 4A).

On responsibility for the implementation and related decisions of assisted colonization projects, $83 \%$ of the respondents strongly agreed or agreed that government agencies (national to sub-national) should be in charge (Fig. 4B), while it was also widely stated that inter-governmental and multi-national agencies (e.g. IUCN) should take responsibilities (77\%). Other stakeholders mentioned by the participating experts were scientists, sub-national government land managers, indigenous peoples, farmers, other landholders, and miners (in the case of restoration sites). 
A

Long-term financial and political commitment in the target area is required for $\mathrm{AC}$ projects

The political stance of an AC recipient country towards AC projects should be assessed. This includes reviewing relevant laws and regulations

$\mathrm{AC}$ project should only be started if there is full authorization and involvement of all relevant government agencies of the beneficiary or host country

Careful assessment of the local citizen attitudes to the proposed AC project are necessary to ensure the continued protection of the migrated population

Socio-economic studies should be carried out for the proposed AC to assess its impacts, costs and benefits for the local human population

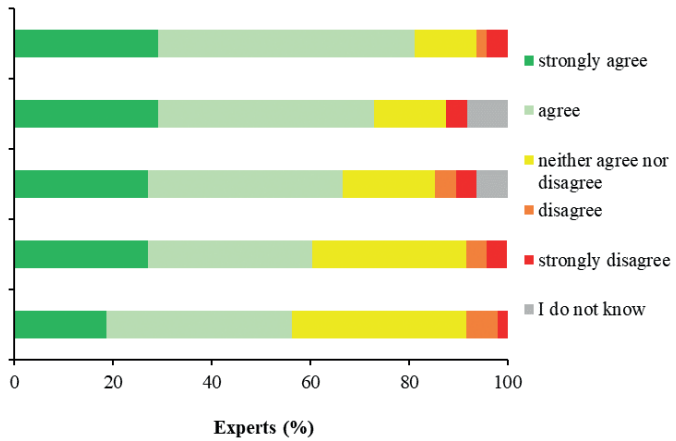

B

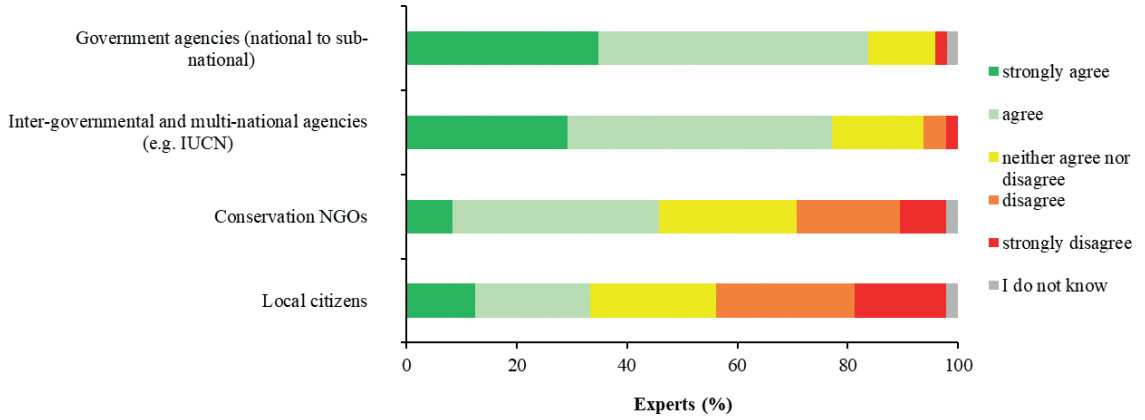

Figure 4. Answers $(n=48)$ to the questions $(\mathbf{A})$ "Please specify the level of agreement with the following statements regarding acceptance of assisted colonization and socio-economic, societal and legal requirement", and (B) "Who should be responsible for the implementation of assisted colonization projects and related decisions?”.

\section{Summary statements on assisted colonization}

A total of $82 \%$ of the respondents strongly agreed or agreed that assisted colonization should be recognized as an effective tool for species conservation but with potential risks that need to be carefully addressed (Fig. 5). In contrast, the overwhelming majority of experts (83\%) denied that assisted colonization is ethically questionable and should be avoided altogether.

\section{Impact of origin on the perception of usefulness and risks of assisted colonization}

We found a statistically significant difference among the answers from respondents of different continents on the usefulness of assisted colonization for (i) the prevention of global species extinction caused by anthropogenic pressures other than climate change (Kruskal-Wallis test: $\mathrm{n}=48 ; \mathrm{df}=4$; Cohen's $\mathrm{d}=0.78 ; \mathrm{p}=0.046$ ), and (ii) for the prevention of regional species extinction caused by climate change (Kruskal-Wallis test: $\mathrm{n}=48$; $\mathrm{df}=4$; Cohen's $\mathrm{d}=0.85 ; \mathrm{p}=0.032$ ). The subsequent post hoc-tests showed that (i) South Americans (median Likert $=2$ ) agreed signifi- 

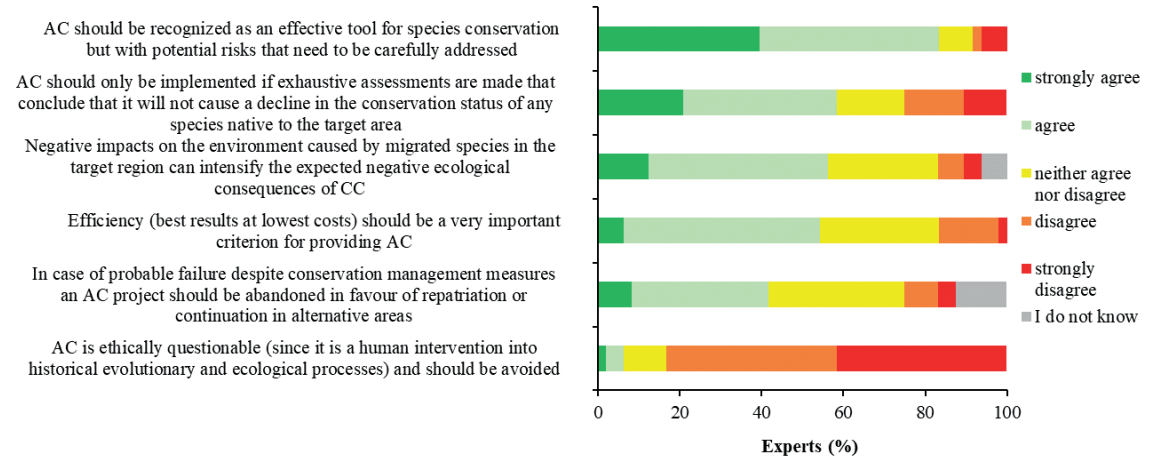

Figure 5. Answers $(\mathrm{n}=48)$ to the question "Please specify the level of agreement with the following statements".

cantly less than North Americans (Mann-Whitney U test: $\mathrm{n}=19$; Cohen's $\mathrm{d}=0.12$; $\mathrm{p}=0.043$ ) and Oceanians (Mann-Whitney U test: $\mathrm{n}=14$; Cohen's $\mathrm{d}=1.44 ; \mathrm{p}=$ 0.032) (median Likert $=4$ in both cases) that assisted colonization is useful when globally endangered species are threatened by anthropogenic pressures other than climate change. On question (ii), the post hoc test showed that Oceanians (median Likert $=4.5$ ) agreed significantly more than Europeans (median Likert $=3.5$ ) that assisted colonization should also be considered for the prevention of regional extinctions (Mann-Whitney U test: $\mathrm{n}=26$; Cohen's $\mathrm{d}=1.92 ; \mathrm{p}=0.007$ ).

\section{The role of respondents' working area on the perception of usefulness and risks of assisted colonization}

Regarding the dependence of favoring assisted colonization on working time spent on related topics, only one of the ten analyzed correlations was statistically significant. Working time in "research on biodiversity and nature conservation (excluding time for research on assisted colonization and climate change impact on biodiversity)" was negatively correlated (Spearman $R h o=-0.32$; Cohen's $d=0.68 ; \mathrm{p}=0.029$ ) to the agreement with the statement "Assisted colonization should be recognized as an effective tool for species conservation but with potential risks that need to be carefully addressed".

\section{Discussion}

\section{General views on the usefulness of assisted colonization}

The expert survey conducted in this study provides a synthesis of the views of world leading experts on assisted colonization. Building on their knowledge, pros and cons of assisted colonization were highlighted. It has to be noted that other target groups (e.g. conservation scientists working in other fields, general public, human populations in 
target regions considered for assisted colonization) might have different views on assisted colonization, which are not considered in this study.

Overall, a substantial majority of participating experts in the present survey were in favor of this conservation strategy and considered assisted colonization as a useful strategy to prevent global species extinction caused by climate change and other anthropogenic pressures. With the publication of the IUCN guidelines on conservation translocations (IUCN/SSC 2013), guidelines regarding risk assessment, regulatory compliance, release strategy, monitoring and management are provided which help to mitigate many of the downsides of assisted colonization. The experts were aware of these possible risks, such as translocated species not being able to establish or threaten native biota. Clearly, assisted colonization should only be applied under certain circumstances. There was a clear difference in the appropriateness of assisted colonization for mitigating natural versus anthropogenic pressures on species. Respondents agreed that to prevent the failure of a translocation, it is crucial that certain precautions are met such as a completed risk assessment, the creation of an adaptive management plan, and detailed monitoring of the target area. Likewise, long-term financial and political support in the target area, as well as relevant legislation are considered essential to successfully implement assisted colonization projects. In view of this, the majority of experts believe that these should be best decided by government- and inter-governmental agencies.

This survey showed that ethical aspects about assisted colonization are considered of modest importance, most likely because protecting threatened species from extinction is considered to be of paramount importance. Nevertheless, ethical considerations in biodiversity conservation in general and assisted colonization in particular require a broad discourse (Minteer and Collins 2005a, 2005b, 2008) with many stakeholders from various part of the society. Taking into account the views of other societal groups might lead to different outcomes but will certainly be necessary when evaluating ethical aspects of assisted colonization. Even among subgroups of the surveyed experts, opinions on assisted colonization differed, with conservation biologists who mainly work on conservation strategies other than assisted colonization being more likely to disagree with assisted colonization. This indicates that perceptions in a broader set of society groups may vary to an even larger degree.

\section{Opportunities of assisted colonization}

Most of the respondents stated that assisted colonization is an appropriate conservation measure to prevent global species extinction caused by climate change and other anthropogenic pressures (e.g. fragmentation, habitat loss, pathogens). The prevention of global species extinction threatened by climate change seems to be the main justification of the respondents of this survey for applying assisted colonization. In the first two decades of the $21^{\text {st }}$ century, the impacts of unfolding climate change on biodiversity have become an urgent global concern (Williams et al. 2003; Deb et al. 2018). However, the experts in the present survey considered assisted colonization not only as a means to overcome barriers that hinder range shifts required to match climatic re- 
quirements of populations (Javeline et al. 2015), but also to prevent extinction caused by other anthropogenic pressures than climate change. This finding reflects the insight that the unfolding global extinction crisis is caused by several interacting pressures (IPBES 2019; Otero et al. 2020).

Previous studies have shown that other conservation strategies (e.g. expanding protected areas, the establishment of corridors, ex situ conservation) are preferred to assisted colonization (Javeline et al. 2015). This view is generally supported by the respondents of this survey, in particular when dealing with threats that are not related to anthropogenic influence or with extinctions at regional level. However, these conservation strategies might not be effective enough to cope with climate change in strongly fragmented landscapes (Wessely et al. 2017). Thus, there is an urgent need to assess critically all potentially applicable conservation strategies (Genovesi and Simberloff 2020).

The analysis showed that most respondents (79\%) considered the use of assisted colonization only appropriate for highly threatened species. In another question, 91\% of respondents viewed assisted colonization only appropriate in cases that cannot be effectively solved by other conservation strategies. Clearly, assisted colonization should be used as the method of last resort. An example could be the Pyrenean desman Galemys pyrenaicus, a semi-aquatic mammal of the family Talpidae inhabiting a small range in northern Spain and Portugal. Climate modelling indicates that this species, already threatened by several pressures, might not survive climate change in its current range (Morueta-Holme et al. 2010). However, streams in western Britain might be suitable habitats for the species (Thomas 2011).

According to the results, the protection status of a species seems not to be the only relevant criterion. Other criteria that were considered relevant such as small climatic niches, poor dispersal capacity compared to the velocity of climate change (Loarie et al. 2009), being a keystone species or a species that is relevant for ecosystem service provision should be taken into account in decisions as to whether a species is suitable for assisted colonization (Hällfors et al. 2017). The importance of species values and the importance of ecological functional properties indicate that different and sometimes competing motivational goals exist to select a species for assisted colonization (Aubin et al. 2011; Hagerman and Satterfield 2014). Thus, fundamental perspectives on nature and causes of its endangerment seem to influence the opinions of experts on assisted colonization (Aubin et al. 2011; Burbidge et al. 2011; Ste-Marie et al. 2011).

Oceanian experts were strongest in favor of applying assisted colonization for the prevention of regional (i.e. as opposed to global) species extinctions. This is probably related to Oceania's distinct insular biogeography, which results in a particularly large number of highly threatened species and the related urgency for applying and testing novel conservation measures (Short 2009; Burbidge et al. 2011; Seddon et al. 2015).

\section{Risks of assisted colonization}

Experts were most concerned about failure of the long-term establishment of the translocated species caused by biotic constraints (e.g. competition, predation, parasitism) in 
the target region. This reflects the difficulty of assessing certain crucial parameters that are essential for planning and implementing assisted colonization projects such as (i) species-specific sensitivity to climate change, dispersal abilities, habitat requirements, habitat availability, (ii) information pertaining to the target region (e.g. biotic interactions among species, land ownership), and (iii) uncertainty about future environmental and climate change trajectories (Hällfors et al. 2017). Each candidate species should be evaluated carefully to judge the balance between potential benefits of helping to save a species from extinction and potential risks to native biota within the recipient area (Thomas 2011). Several systematic processes are suggested for identifying potentially suitable sites for translocation. For instance, multiple criteria analysis (MCA) facilitates the assessment on whether (i) assisted colonization is well planned and monitored, (ii) could be a possible contribution to achieve conservation goals and (iii) will ultimately result in the establishment of long-term sustainable populations (Carroll et al. 2009; Miller et al. 2012; Dade et al. 2014).

The results of our survey showed that a rather high percentage of experts were concerned about the transmission of diseases and, more generally, the emergence of invasive behavior in the recipient region potentially threating native biota. For instance, the potential invasive spread of the target species and unforeseen pathogen transmission to native species in the recipient region are plausible and potentially highly impactful scenarios (Aubin et al. 2011; Pedlar et al. 2012; Ferrarini et al. 2016). From invasion science it is well-known that the transport of animals and plants by humans spreads disease-causing pathogens (Collins and Crump 2009; Rabitsch et al. 2017) and promotes the spillover to new host species (Slippers et al. 2005). Assisted colonization may entail similar risks. An example is the introduction of the American red squirrel Tamiasciurus hudsonicusto into Newfoundland. Assisted colonization was done partly to improve the diet of the pine marten (Martes americana), a declining species. However, a previously unexpected competition with birds for black spruce cones as a food resource developed, which might have resulted in the decline of the Newfoundland red crossbill (Loxia curvirostra percna) (Schwartz 2005). Several respondents expressed concerns over the potential impacts of translocated species on cultural and aesthetic values of the recipient region particularly if they potentially become conspicuous or abundant (Palmer and Larson 2014). On the other side, the loss of a species in its original range also may affect cultural values (Sandler 2013; Palmer and Larson 2014). Assisted colonization cannot fully restore such context-specific values, but preserving a species offers the opportunity to preserve the values attached to the species in question.

\section{Reducing risks of assisted colonization projects}

This study showed that the following measures are considered most relevant by the respondents to enable successful assisted colonization: (i) selecting a target area with a carrying capacity large enough to sustain a minimum viable population, (ii) identification and protection of climate change refugia, and (iii) implementation of adaptive management to minimize the risk that the migrant population fails to establish in the target area. 
As a necessity to justify assisted colonization as an effective conservation tool, careful study, risk management, and supported implementation are essential (Mueller and Hellmann 2008). Of particular importance for the success of assisted colonization projects is assessing habitat suitability and availability to the needs of the candidate species (IUCN/SSC 2013). The determination of carrying capacity and estimates on climate change refugia are additional crucial criteria for identifying suitable regions for the translocated species and to ensure successful establishment (Hällfors et al. 2017). For instance, climate models that show future climate changes in relation to the tolerance limits of species could be a useful tool to obtain appropriate information (IUCN/SSC 2013). Further, in the case of translocation by assisted colonization, the implementation of management measures is essential and depends on monitoring results, which create the basis for progressive or adaptive management measures.

In order to minimize negative effects on native biota, a majority of the respondents considered that one of the most relevant activities should be monitoring of the target region and adjacent areas to identify potential negative impacts. The IUCN/ SSC (2013) guidelines highlight that monitoring in the course of a translocation is essential. Thus, before the implementation of an assisted colonization project, it is important to evaluate the effects of future climate scenarios on ecological and hydrological processes of the recipient ecosystem (Carroll et al. 2009), to monitor target species and their social environment (Schwartz and Martin 2013) and to evaluate the predictions through species distribution models (Hällfors et al. 2017). This also includes monitoring to identify new threats to the translocated population which were not part of translocation design to minimize the risk that the translocated population fails to establish in the target area (IUCN/SSC 2013). Finally, assessing and monitoring demography, behavior, ecological functions, genetics, health conditions and mortality, social, cultural, and economic interest of the translocated species are important (IUCN/SSC 2013).

\section{Acceptance and implementation of assisted colonization}

Evidently, assisted colonization has to comply with laws and international regulations, e. g. with the World Organisation for Animal Health standards for animal movement and those of the International Plant Protection Convention (IUCN/SSC 2013). Compatibility with logistic constraints on land use in the target regions need to be taken into account (IUCN/SSC 2013). But beyond logistic aspects, further implementation criteria need to be considered.

A large majority of experts considered secured financial and political commitment and appropriate regulatory frameworks as necessary preconditions for implementing assisted colonization. Costs for implementing assisted colonization are highly contextspecific and can result from a wide array of measures such as captive breeding of the target species, monitoring, and land purchase (Pedlar et al. 2012). The IUCN/SSC (2013) guidelines highlight that there should be awareness of possible needs for funding from any damage caused by the translocated species. Furthermore, flexible budget 
plans should be available to allow for adaptive changes to an assisted colonization project during implementation.

In terms of responsibility for the implementation and related decisions of assisted colonization projects, most of the respondents held the opinion that this should be the task of government agencies and inter-governmental and multi-national agencies (e.g. IUCN). Government agencies and multinational agencies should not only assume responsibility but should also collaborate intensively with conservation science to identify potential benefits and risks that could become important contributions for advancing the development standards and guidelines for assisted colonization (Javeline at al. 2015). Further, cooperation between the various stakeholders is needed to minimize the risk of poor implementation of assisted colonization projects (Javeline at al. 2015).

\section{Conclusions}

While it is clear that assisted colonization is a conservation tool that can only be applied to a rather limited number of species, this study reveals substantial backing from the surveyed conservation experts for improving the survival prospects of threatened species by assisted colonization as a useful conservation strategy under rapid environmental change, when other conservation strategies are not an available option. Experts most strongly support assisted colonization for pressures related to climate change, but also are in favor of assisted colonization as a management option for other anthropogenic threats. However, experts clearly expressed concerns on possible risks and negative consequences that are inherent to assisted colonization. Therefore, the approval of this conservation method is bound by several requirements such as (i) a collection of precise species-specific data of needs and conditions, (ii) a completed exhaustive risk assessment, (iii) a clarification of any legal or financial obstacles, (iv) implementation of previously defined management measures, and (v) further monitoring of target areas to successfully establish the translocated species while protecting native biota. Accordingly, reducing the risks caused by possible disease and pathogen transmissions, potential invasiveness of the translocated species and failure of long establishment are required.

\section{Acknowledgements}

We are grateful to all the experts who have supported this study by completing the survey. The contributions by K.P.Z. and S.S. were funded by the Austrian Climate and Energy Fund within the framework of the "Austrian Climate Research Programme" (Project "Conservation under Climate Change: Challenges, Constraints and Solutions"; Number KR17AC0K13678). FE was funded through the 2017-2018 Belmont Forum and BiodivERsA joint call for research proposals, under the BiodivScen ERA-Net COFUND programme with Project "Alien Scenarios" (FWF project no I 4011-B32). We appreciate the comments of two anonymous reviewers that helped to improve the manuscript. 


\section{References}

Aubin I, Garbe CM, Colombo S, Drever CR, McKenney DW, Messier C, Pedlar J, Saner MA, Venier L, Wellstead AM, Winder R, Witten E, Ste-Marie C (2011) Why we disagree about assisted migration: Ethical implications of a key debate regarding the future of Canada's forests. Forestry Chronicle 87(06): 755-765. https://doi.org/10.5558/tfc2011-092

Bortz J, Schuster C (2010) Statistik für Human- und Sozialwissenschaftler $\left(7^{\text {th }}\right.$ edn.). Springer, Heidelberg. https://doi.org/10.1007/978-3-642-12770-0

Braun M, Schindler S, Essl F (2016) Distribution and management of invasive alien plant species in protected areas in Central Europe. Journal for Nature Conservation 33: 48-57. https://doi.org/10.1016/j.jnc.2016.07.002

Burbidge AA, Byrne M, Coates D, Garnett ST, Harris S, Hayward MW, Martin TG, McDonald-Madden E, Mitchell NJ, Nally S, Setterfield SA (2011) Is Australia ready for assisted colonization? Policy changes required to facilitate translocations under climate change. Pacific Conservation Biology 17(3): 259-269. https://doi.org/10.1071/PC110259

Carroll MJ, Anderson BJ, Brereton TM, Knight SJ, Kudrna O, Thomas CD (2009) Climate change and translocations: The potential to re-establish two regionally extinct butterfly species in Britain. Biological Conservation 142(10): 2114-2121. https://doi.org/10.1016/j. biocon.2009.04.010

Collins JP, Crump ML (2009) Extinction in our times. Global amphibian decline. Oxford University Press, Oxford.

Dade MC, Pauli N, Mitchell NJ (2014) Mapping a new future: Using spatial multiple to identify novel habitats for assisted colonization of endangered species. Animal Conservation 17: 4-17. https://doi.org/10.1111/acv.12150

Dawson TP, Jackson ST, House JI, Prentice IC, Mace GM (2011) Beyond predictions: Biodiversity conservation in a changing climate. Science 332(6025): 53-58. https://doi. org/10.1126/science. 1200303

Deb JC, Phinn S, Butt N, McAlpine CA (2018) Adaptive management and planning for the conservation of four threatened large Asian mammals in a changing climate. Mitigation and Adaptation Strategies for Global Change 24: 1-22. https://doi.org/10.1007/s11027018-9810-3

Díaz S, Settele J, Brondízio ES, Ngo HT, Agard J, Arneth A, Balvanera P, Brauman KA, Butchart SHM, Chan KMA, Garibaldi LA, Ichii K, Liu J, Subramanian SM, Midgley GF, Miloslavich P, Molnár Z, Obura D, Pfaff A, Polasky S, Purvis A, Razzaque J, Reyers B, Chowdhury RR, Shin Y-J, Visseren-Hamakers I, Willis KJ, Zayas CN (2019) Pervasive human-driven decline of life on Earth points to the need for transformative change. Science 366(6471): 6471-6480. https://doi.org/10.1126/science.aax3100

Donlan C, Wingfield DK, Crowder LB, Wilcox C (2010) Using expert opinion surveys to rank threats to endangered species: A case study with sea turtles. Conservation Biology 24(6): 1586-1595. https://doi.org/10.1111/j.1523-1739.2010.01541.x

Ferrarini A, Selvaggi A, Abeli T, Alatalo JM, Orsenigo S, Gentili R, Rossi G (2016) Planning for assisted colonization of plants in a warming world. Scientific Reports 6(1): 28542. https:// doi.org/10.1038/srep28542 
Fischer J, Lindenmayer DB (2000) An assessment of the published results of animal relocations. Biological Conservation 96(1): 1-11. https://doi.org/10.1016/S0006-3207(00)00048-3

Genovesi P, Simberloff D (2020) "De-extinction” in conservation: Assessing risks of releasing "resurrected" species. Journal for Nature Conservation 56: 125838. https://doi. org/10.1016/j.jnc.2020.125838

Gray LKY, Gylander T, Mbogga MS, Chen P, Hamann A (2011) Assisted migration to address climate change: Recommendations for aspen reforestation in western Canada. Ecological Applications 21(5): 1591-1603. https://doi.org/10.1890/10-1054.1

Grimm NB, Staudinger MD, Staudt A, Carter SL, Chapin FS III, Kareiva P, Ruckelshaus M, Stein BA (2013) Climate-change impacts on ecological systems: Introduction to a US assessment. Frontiers in Ecology and the Environment 11(9): 456-464. https://doi. org/10.1890/120310

Hagerman SM, Satterfield T (2014) Agreed but not preferred: Expert views on taboo options for biodiversity conservation, given climate change. Ecological Applications 24(3): 548559. https://doi.org/10.1890/13-0400.1

Hällfors MH, Vaara E, Hyvarinen M, Lehvavirta S (2014) Coming to Terms with the Concept of Moving Species Threatened by Climate Change - A Systematic Review of the Terminology and Definitions. PLoS ONE 7(7): e102979. https://doi.org/10.1371/journal. pone.0102979

Hällfors MH, Aikio S, Schulman LE (2017) Quantifying the need and potential of assisted migration. Biological Conservation 205: 34-41. https://doi.org/10.1016/j.biocon.2016.11.023

Hoegh-Guldberg HL, McIntyre HS, Lindenmayer DB, Parmesan C, Possingham HP, Thomas CD (2008) Assisted colonization and rapid climate change. Science 321(5887): 345-346. https://doi.org/10.1126/science.1157897

Hunter ML (2007) Climate Change and Moving Species: Furthering the Debate on Assisted Colonization. Conservation Biology 21(5): 1356-1358. https://doi.org/10.1111/j.15231739.2007.00780.x

IPBES (2019) Summary for policymakers of the global assessment report on biodiversity and ecosystem services of the Intergovernmental Science-Policy Platform on Biodiversity and Ecosystem Services. IPBES Secretariat, Bonn.

IUCN (2021) The IUCN Red List of Threatened Species. https://www.iucnredlist.org

IUCN/SSC (2013) Guidelines for Reintroductions and Other Conservation Translocations Version 1.0. IUCN Species Survival Commission.

Javeline D, Hellmann JJ, Cornejo RC, McLachlan JS, Sax DF, Schwartz MW, Cornejo RC (2015) Expert opinion on extinction risk and climate change adaptation for biodiversity. Elementa. Science of the Anthropocene 3: 57. https://doi.org/10.12952/journal.elementa.000057

Likert R (1932) A technique for the measurement of attitudes. Archives de Psychologie 140: $1-55$.

Lloyd NA, Hostetter NJ, Jackson CL, Converse SJ, Moehrenschlager A (2019) Future directions to escalate benefits of the stepping-stone approach for conservation translocations. Animal Conservation 22(2): 122-123. https://doi.org/10.1111/acv.12506 
Loarie SR, Duffy PB, Hamilton H, Asner GP, Field CB, Ackerly DD (2009) The velocity of climate change. Nature 462(7276): 1052-1055. https://doi.org/10.1038/nature08649

Loss SR, Terwilliger LA, Peterson AC (2011) Assisted colonization: Integrating conservation strategies in the face of climate change. Biological Conservation 144(1): 92-100. https:// doi.org/10.1016/j.biocon.2010.11.016

Ma A, Bohan DA, Canard E, Derocles SAP, Gray C, Lu X, Macfadyen S, Romero GQ, Kratina P (2018) Chapter seven - a replicated network approach to 'Big Data' in ecology. Advances in Ecological Research 59: 225-264. https://doi.org/10.1016/bs.aecr.2018.04.001

McKight PE, Najab J (2010) Kruskal-Wallis-Test. The Corsini Encyclopedia of Psychology. J. Wiley \& Sons Inc., New York. https://doi.org/10.1002/9780470479216.corpsy0491

McLachlan JS, Clark JS, Manos PS (2005) Molecular indicators of tree migration capacity under rapid climate change. Ecology 86(8): 2088-2098. https://doi.org/10.1890/04-1036

McLachlan JS, Hellmann JJ, Schwartz MW (2007) A framework for debate of assisted migration in an era of climate change. Conservation Biology 21(2): 297-302. https://doi. org/10.1111/j.1523-1739.2007.00676.x

Miller KA, Miller HC, Moore JA, Mitchell NJ, Cree A, Allendorf FW, Sarre SD, Keall SN, Nelson NJ (2012) Securing the Demographic and Genetic Future of Tuatara Through Assisted Colonization. Conservation Biology 26(5): 790-798. https://doi.org/10.1111/ j.1523-1739.2012.01902.x

Minteer BA, Collins JP (2005a) Why we need an "ecological ethics". Frontiers in Ecology and the Environment 3: 332-337. https://doi.org/10.1890/1540-9295(2005)003[0332:WW NAEE]2.0.CO;2

Minteer BA, Collins JP (2005b) Ecological ethics: Building a new tool kit for ecologists and biodiversity managers. Conservation Biology 19(6): 1803-1812. https://doi.org/10.1111/ j.1523-1739.2005.00281.x

Minteer BA, Collins JP (2008) From environmental to ecological ethics: Toward a practical ethics for ecologists and conservationists. Science and Engineering Ethics 14(4): 483-501. https://doi.org/10.1007/s11948-008-9087-0

Minteer C, Collins JP (2010) Move it or lose it? The ecological ethics of relocating species under climate change. Ecological Applications 20(7): 1801-1804. https://doi.org/10.1890/10-0318.1

Morueta-Holme N, Fløjgaard C, Svenning J-C (2010) Climate change risks and conservation Implications for a threatened small-range mammal species. PLoS ONE 5(4): e10360. https://doi.org/10.1371/journal.pone.0010360

Mueller JM, Hellmann JJ (2008) An assessment of invasion risk from assisted migration. Conservation Biology 22(3): 562-567. https://doi.org/10.1111/j.1523-1739.2008.00952.x

Otero I, Farrell KN, Pueyo S, Kallis G, Kehoe L, Haberl H, Plutzar C, Hobson P, GarcíaMárquez J, Rodríguez-Labajos B, Martin JL, Erb KH, Schindler S, Nielsen J, Skorin T, Settele J, Essl F, Gómez-Baggethun E, Brotons L, Rabitsch W, Schneider F, Pe’er G (2020) Biodiversity policy beyond economic growth. Conservation Letters 13(4): e12713. https:// doi.org/10.1111/conl.12713

Palmer C, Larson BMH (2014) Should we move the Whitebark Pine? Assisted Migration, Ethics and Global Environmental Change. Environmental Values 23(6): 641-662. https:// doi.org/10.3197/096327114X13947900181833 
Parmesan C, Yohe G (2003) A globally coherent fingerprint of climate change impacts across natural systems. Nature 421(6918): 37-42. https://doi.org/10.1038/nature01286

Pedlar JH, McKenney DW, Aubin I, Beardmore T, Beaulieu J, Iverson L, O’Neill GA, Winder RS, Ste-Marie C (2012) Placing forestry in the assisted migration debate. BioScience 62(9): 835-842. https://doi.org/10.1525/bio.2012.62.9.10

Pe'er G, Zinngrebe Y, Hauck J, Schindler S, Dittrich A, Zingg S, Tscharntke T, Oppermann R, Sutcliffe L, Sirami C, Schmidt J, Hoyer C, Schleyer C, Lakner S (2017) Adding some green to the greening: Improving the EU's Ecological Focus Areas for biodiversity and farmers. Conservation Letters 10(5): 517-530. https://doi.org/10.1111/conl.12333

Pe'er G, Zinngrebe Y, Moreira F, Sirami C, Schindler S, Müller R, Bontzorlos V, Clough D, Bezak P, Bonn A, Hansjürgens B, Lomba A, Möckel S, Passoni G, Schleyer C, Schmidt J, Lakner S (2019) A greener path for the EU Common Agricultural. Policy Sciences 365: 449-451. https://doi.org/10.1126/science.aax3146

Probert AF, Ward DF, Beggs JR, Lin S, Stanley MC (2019) Conceptual Risk Framework: Integrating Ecological Risk of Introduced Species with Recipient Ecosystems. Bioscience 70: 71-79. https://doi.org/10.1093/biosci/biz131

Rabitsch W, Essl F, Schindler S (2017) The rise of non-native vectors and reservoirs of human diseases. In: Vilà M, Hulme PE (Eds) Impact of biological invasions on ecosystem services. Springer, Cham, 263-275. https://doi.org/10.1007/978-3-319-45121-3_17

Ricciardi A, SimberloffD (2009) Assisted colonization is not a viable conservation strategy. Trends in Ecology \& Evolution 24(5): 248-253. https://doi.org/10.1016/j.tree.2008.12.006

Ricciardi A, Simberloff D (2014) Fauna in decline: First do no harm. Science 345(6199): 884-884. https://doi.org/10.1126/science.345.6199.884-b

Root TL, Price JT, Hall KR, Schneider SH, Rosenweig C, Pounds JA (2003) Fingerprints of global warming on animals and plants. Nature 421(6918): 57-60. https://doi.org/10.1038/ nature 01333

Sandler R (2013) Climate change and ecosystem management. Ethics, Policy \& Environment 16: 1-15. https://doi.org/10.1080/21550085.2013.768377

Sax DF, Smith KF, Thompson AR (2009) Managed relocation: A nuanced evaluation is needed. Trends in Ecology \& Evolution 24(9): 472-473. https://doi.org/10.1016/j. tree.2009.05.004

Schwartz M (2005) Conservationists should not move Torreya taxifolia. Wild Earth 10: 1-4.

Schwartz MW, Martin TG (2013) Translocation of imperiled species under changing climates. Annals of the New York Academy of Sciences Biology 1286(1): 15-28. https://doi. org/10.1111/nyas. 12050

Schwartz MW, Hellmann JJ, McLachlan JS (2009) The precautionary principle in managed relocation is misguided advice. Trends in Ecology \& Evolution 24(9): 474. https://doi. org/10.1016/j.tree.2009.05.006

Seddon PJ, Armstrong DP, Soorae P, Launay F, Walker S, Ruiz-Miranda CR, Molur S, Koldeway H, Kleiman DG (2009) The risks of assisted colonization. Conservation Biology 23(4): 788-789. https://doi.org/10.1111/j.1523-1739.2009.01200.x 
Seddon PJ, Moro D, Mitchell N, Chauvenet ALM, Mawson PR (2015) Proactive conservation or planned invasion? Past, current and future use of assisted colonisation. In: Armstrong D, Hayward M, Moro M, Seddon P (Eds) Advances in reintroduction biology of Australian and New Zealand Fauna. Csiro Publishing, 105-126.

Semenchuk Ph, Moser D, Essl F, Schindler S, Wessely J, Gattringer A, Dullinger S (2021) Future representation of species' climatic niches in protected areas: A case study with Austrian endemics. Frontiers in Ecology and Evolution 9: e685753. https://doi.org/10.3389/ fevo.2021.685753

Short J (2009) The characteristics and success of vertebrate translocations within Australia: a progress report to Department of Agriculture, Fisheries and Forestry.

Slippers B, Stenlid J, Wingfield MJ (2005) Emerging pathogens: Fungal host jumps following anthropogenic introduction. Trends in Ecology \& Evolution 20(8): 420-421. https://doi. org/10.1016/j.tree.2005.05.002

Ste-Marie C, Nelson EA, Dabros A, Bonneau M (2011) Assisted migration: Introduction to a multifaceted concept. Forestry Chronicle 87: 724-730. https://doi.org/10.5558/ tfc2011-089

Thomas C (2011) Translocation of species, climate change, and the end of trying to recreate past ecological communities. Trends in Ecology \& Evolution 26(5): 216-221. https://doi. org/10.1016/j.tree.2011.02.006

Urban MC (2015) Accelerating extinction risk from climate change. Science 348(6234): $571-$ 573. https://doi.org/10.1126/science.aaa4984

Vitt P, Havens K, Hoegh-Guldberg O (2009) Assisted migration: Part of an integrated conservation strategy. Trends in Ecology \& Evolution 24(9): 473-474. https://doi.org/10.1016/j. tree.2009.05.007

Wessely J, Hülber K, Gattringer A, Kuttner M, Moser D, Rabitsch W, Schindler S, Dullinger S, Essl F (2017) Severe constraints for the effectiveness of conservation strategies to mitigate climate change-induced range losses. Nature Climate Change 7: 823-827. https://doi. org/10.1038/nclimate3414

Williams SE, Bolitho EE, Fox S (2003) Climate change in Australian tropical rainforests: An impending environmental catastrophe. Proceedings of the Royal Society of London. Series B, Biological Sciences 270(1527): 1887-1892. https://doi.org/10.1098/ rspb.2003.2464

Willis S, Hill J, Thomas C, Roy D, Fox R, Blakeley D, Huntley B (2009) Assisted colonization in a changing climate: A test-study using two UK butterflies. Conservation Letters 2(1): 45-52. https://doi.org/10.1111/j.1755-263X.2008.00043.x

Wohlin C (2014) Guidelines for snowballing in systematic literature studies and a replication in software engineering. In: Proceedings of the $18^{\text {th }}$ International Conference on Evaluation and Assessment in Software Engineering, 1-10. https://doi. org/10.1145/2601248.2601268

Wolf C, Best H [Eds] (2010) Handbuch der sozialwissenschaftlichen Datenanalyse. Verlag für Sozialwissenschaften, Heidelberg. https://doi.org/10.1007/978-3-531-92038-2 


\section{Supplementary material I}

\section{Figure S1}

Authors: Irma Kracke, Franz Essl, Klaus Peter Zulka, Stefan Schindler

Data type: Figure (docx. file)

Explanation note: Figure S1. Geographical affiliation of (a) the authors of scientific articles $(n=264)$ on assisted colonization (assignment of the lead authors and co-authors was done based on Internet research at which institute they carried out their research), and of (b) the authors of scientific articles who took part in the survey $(\mathrm{n}=48)$ on assisted colonization.

Copyright notice: This dataset is made available under the Open Database License (http://opendatacommons.org/licenses/odbl/1.0/). The Open Database License $(\mathrm{ODbL})$ is a license agreement intended to allow users to freely share, modify, and use this Dataset while maintaining this same freedom for others, provided that the original source and author(s) are credited.

Link: https://doi.org/10.3897/natureconservation.45.72554.suppl1

\section{Supplementary material 2}

\section{The questions used in the online survey}

Authors: Irma Kracke, Franz Essl, Klaus Peter Zulka, Stefan Schindler

Data type: docx. file

Explanation note: The questions used in the online survey.

Copyright notice: This dataset is made available under the Open Database License (http://opendatacommons.org/licenses/odbl/1.0/). The Open Database License $(\mathrm{ODbL})$ is a license agreement intended to allow users to freely share, modify, and use this Dataset while maintaining this same freedom for others, provided that the original source and author(s) are credited.

Link: https://doi.org/10.3897/natureconservation.45.72554.suppl2 